\title{
Dynamiken i smålommens Gavia stellata val av häckningslokaler - övergivande, ny- och återetableringar
}

\author{
Dynamics of breeding site choice of Red-throated Loon Gavia stellata - \\ abandonments, new establishments and reoccupations
}

\author{
MATS O.G. ERIKSSON \& MATTI ÅHLUND
}

\begin{abstract}
Red-throated Loons Gavia stellata have disappeared from breeding sites regularly used in the mid-1990s, but it is not clear if this reflects a population decline or movements to other sites. Therefore, we searched for potential breeding sites, including sites with old records, in three regions in southern Sweden, where it was possible to repeat surveys conducted in the past. A pattern of abandonment and return to breeding sites was verified; around $30 \%$ of the sites were abandoned over a 10 -year period, but the loss was largely compensated by establishment at new sites or return to sites used in the past. But almost one quarter of the sites were used in about $75 \%$ of the breeding seasons across a period of more than 30 years.

Annual breeding success at these sites did not differ from that at the other, less frequently used sites. However, the most continuously used sites produce a larger total of young than other sites and are therefore important for long-term recruitment. They should be identified and prioritised for protection and management.

Mats O. G. Eriksson, MK Natur- och Miljökonsult, Tommeredsvägen 23, 43792 Lindome.

E-mail: eriksson.tommered@telia.com.

Matti Ahlund, Hemmetvägen 24, 45296 Strömstad.

E-mail: matti.ahlund@telia.com.
\end{abstract}

Received 5 May 2013, Accepted 11 October 2013, Editor J. Waldenström

Smålommen Gavia stellata har länge uppmärksammats i det svenska fågelskyddsarbetet mot bakgrund av farhågor för en långsiktigt minskande trend och en låg ungproduktion (t.ex. Eriksson 2010). Hotbilden är komplex och innefattar bland annat direkt eller indirekt påverkan av markavvattning vid häckningstjärnarna och utglesade bestånd av bytesfisk (främst laxartad och mörtartad fisk) i fiskevattnen.

Mot denna bakgrund initierades Projekt LOM 1994 gemensamt av Sveriges Ornitologiska Förening och Svenska Naturskyddsföreningen. Kärnverksamheten har sedan dess varit att inventera och fastställa häckningsutfallet för storlom och smålom (se Eriksson 2012 för en sammanställning för perioden 1994-2011). Inom ramen för inventeringarna har flera rapportörer noterat att många smålomstjärnar som var regelbundet bebodda av häckande fåglar under mitten och slutet av 1990-talet har stått tomma under senare år, men det har varit oklart om detta beror på en minskning av populationens storlek eller på en omflyttning till andra häckningstjärnar.

Det finns indikationer på att en reell minskning har ägt rum. Vid en återupprepning av en inven- tering av smålomsbeståndet i Sunne kommun i Värmland fann man att antalet häckande par minskat från 30-35 par under 1980-talet till ungefär 25 par 2005 (Schützer \& Schütt 2005). Inventeringarna inom Projekt LOM visar att smålommens häckningsframgång kan ha varit för låg för att kompensera för den årliga dödligheten på Sydsvenska Höglandet och i artens svenska kärnområde i Svealand, medan häckningsutfallet har varit bättre i Norrland (Eriksson 2012).

Det är en allmänt spridd uppfattning att det sydsvenska smålomsbeståndet har varit på tillbakagång under lång tid (t.ex. Svensson et al. 1999, sid. 22-23), men trenden under de senaste årtiondena är svårtydd och motsägelsefull. Det svenska smålomsbeståndet minskade med 10-19\% över en period på ungefär 30 år från mitten av 1970-talet och framåt, men minskningen avstannade mot slutet av denna period (Ottvall et al. 2008). Resultaten från Svensk Fågeltaxering visar att smålommen har ökat i landets norra delar under de senaste årtiondena, medan det finns en antydd men ej statistiskt säkerställd minskning i södra Sverige (Lindström \& Green 2013).

För att öka kunskapen om smålommens be- 


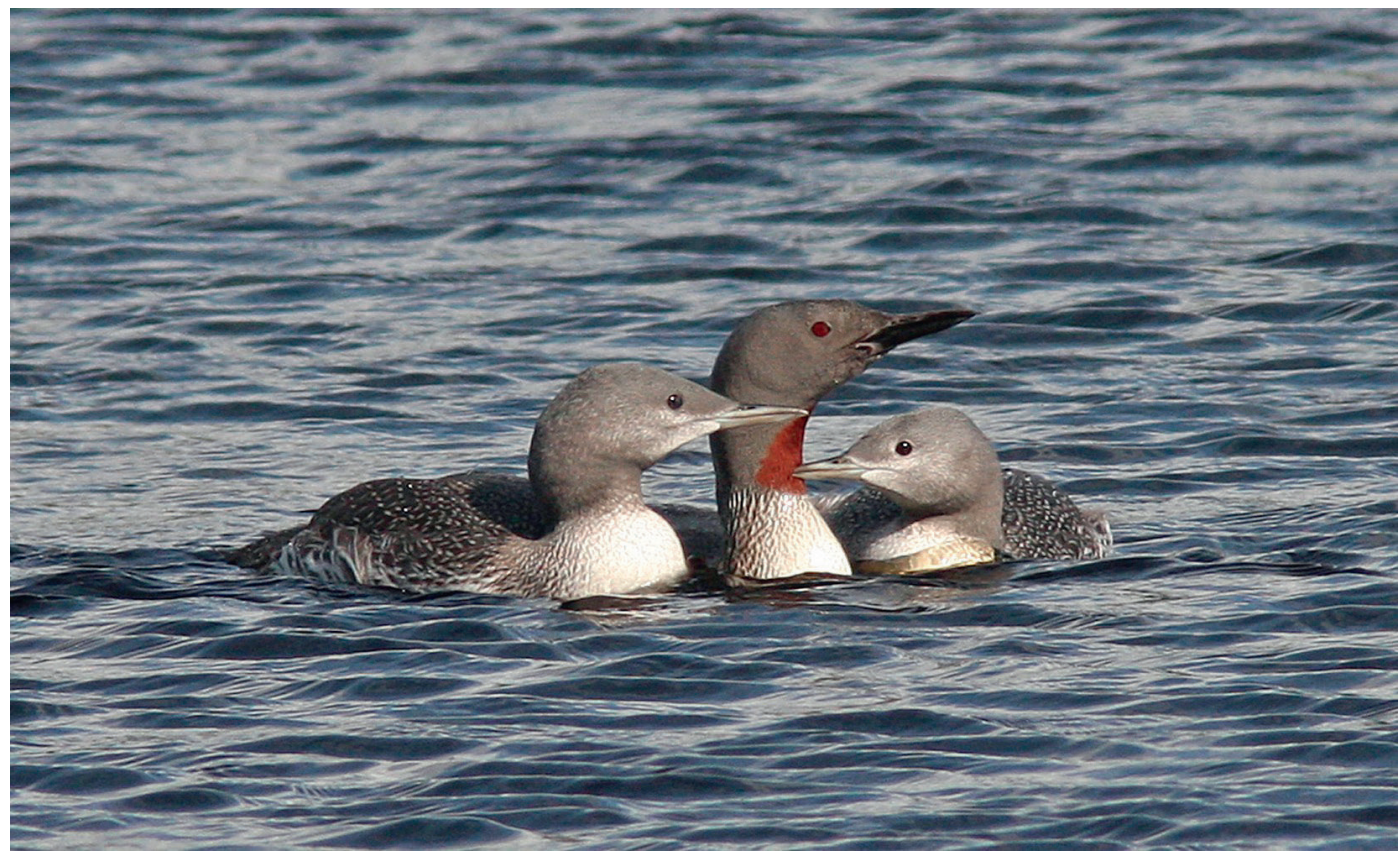

Smålomsförälder med två snart flygga ungar i en häckningstjärn i Dalsland. Foto: Matti Åhlund.

Red-throated Loon parent with two soon fledged chicks at a breeding site in the province of Dalsland. Photo: Matti Ahlund.

ståndsutveckling beslöt Projekt LOM att komplettera det ordinarie fältarbetet med eftersök av smålommar på potentiella häckningslokaler i södra och mellersta Sverige, inklusive återbesök av "gamla" häckningslokaler för arten, med syftet att belysa följande frågeställningar:

- Har det skett en reell tillbakagång i landets södra och mellersta delar?

- Har artens försvinnande från en del häckningslokaler kompenserats genom åter- eller nyetablering i andra häckningstjärnar?

Fältarbetet genomfördes i tre undersökningsområden (Figur 1): (1) Eftersök av häckande smålommar i ett område i sydvästra Sverige, där två undersökningar av smålommens häckningsframgång och val av häckningslokaler tidigare har utförts (Eriksson et al. 1988, Eriksson \& Johansson 1997). Fältarbetet utfördes 2009-2011. Det omfattade återbesök vid lokaler med gamla fynduppgifter, samt besök vid småsjöar och tjärnar utan tidigare information om häckande smålommar men som bedömts vara lämpliga vid studier av kartor m.m. (2) Jämförelse av smålommens förekomst i Dalsland under perioden 1944-1962, med ledning av Nils-Gerhard Karviks originalanteckningar från hans inventeringar av vertebratfaunan i landskapet (Karvik 1964), och den period då Projekt LOM

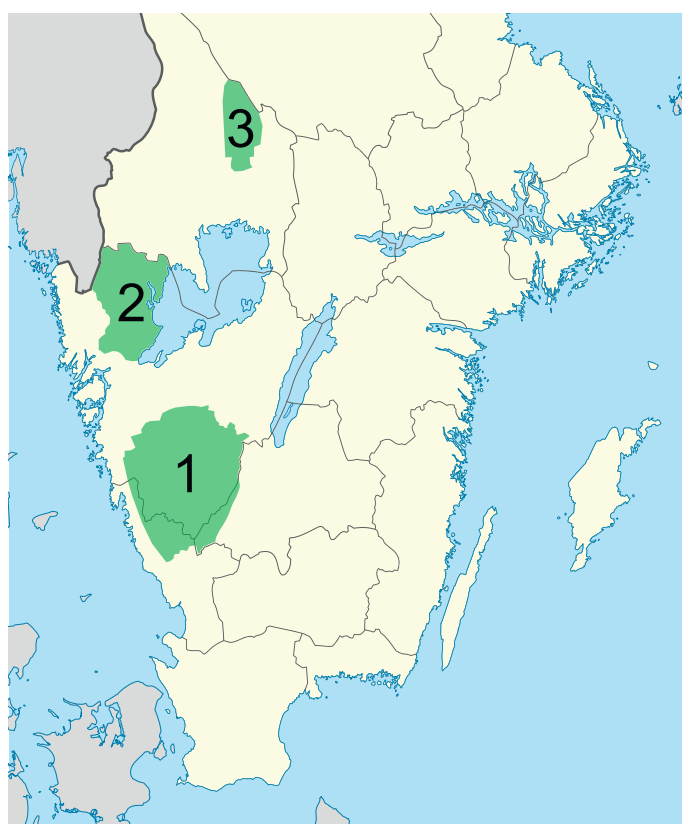

Figur 1. Undersökningsområdena: 1. Sydvästra Sverige, 2. Dalsland, 3 Hagfors kommun.

The study areas: 1. South-western Sweden, 2. Dalsland, 3. Hagfors Municipality. 
arbetat, 1994-2012, dvs. ett halvsekel senare. (3) Återbesök av huvuddelen av de lokaler i Hagfors kommun i Värmland som ingick i en kommuntäckande inventering 1995 (Borgström 1996). Fältarbetet utfördes 2010. I det följande redovisas metodik och resultat separat för vart och ett av de tre undersökningsområdena.

\section{Sydvästra Sverige}

Undersökningsområdet omfattade Bollebygds, Borås, Herrljunga, Härryda, Lerums, Marks, Mölndals, Svenljunga, Tranemo, Ulricehamns och Vårgårda kommuner i Västra Götalands län, de inre delarna av Falkenbergs, Kungsbacka och Varbergs kommuner i Hallands län, samt den del av Gislaveds kommun i Jönköpings län som ligger väster om riksväg 26.

För huvuddelen av det aktuella området finns en ganska god (om än inte komplett) bild av förekomsten av smålom från ungefär 1940-talet och framåt, främst genom en enkät som dåvarande Södra Älvsborgs Ornitologiska Förening gjorde (men aldrig publicerade) i början av 1980-talet, och det inventeringsarbete som föreningen därefter utförde fram till början av 1990-talet (t.ex. Eriksson \& Johansson 1997). Från omkring 1980 bedömdes underlaget vara av tillräcklig kvalitet för analyser av förekomsten av smålom på olika häckningsplatser på basis av 10-årsintervall.

Fältarbetet har totalt omfattat 149 småsjöar och tjärnar. Vid undersökningens början 2009 fanns uppgifter om häckande smålommar, utan någon tidsbegränsning bakåt, för 84 av tjärnarna, varav huvuddelen (78 tjärnar, 93\%) har ingått i undersökningen. Drygt hälften (52\%) av de undersökta tjärnarna var alltså kända som häckningsplatser för smålom när fältarbetet påbörjades.

\section{Metodik}

Förekomsten av smålom bestämdes genom att de 149 tjärnarna besöktes vid minst två tillfällen under minst ett av åren 2009, 2010 och/eller 2011, med ett första besök omkring 1 juni ( \pm två veckor) för eftersök av par och ruvande fåglar och ett andra besök omkring 15 juli ( \pm två veckor) för eftersök av ungar. Tjärnar utan smålommar vid det första besöket besöktes även under den andra perioden, för att minska risken att förbise ruvande fåglar eller sent påbörjade häckningar. Vid observation av smålommar anpassades antalet fortsatta besök till behovet av uppföljning av häckningsresultatet och av ungarnas tillväxt. Fältarbetet gjordes med sam- ma metod som inom de ordinarie inventeringarna $\mathrm{i}$ Projekt LOM, dvs. med noteringar om förekomsten av smålommar (ensamma, i par eller andra grupperingar), eventuella kriterier på häckning (t.ex. parning, bo, ägg, ruvande fågel) samt förekomsten av ungar (antal, storleksklass; se bilaga 1 i Eriksson 2010 för detaljer).

Resultatet för 2009-2011 har ställts i relation till uppgifter om förekomsten av häckande smålommar under minst ett år före 1979 samt 10-årsperioderna 1979-1988, 1989-1998 och 1999-2008. Dynamiken i smålomsbeståndet, dvs. hur omfattande omflyttningen mellan olika tjärnar har varit, undersöktes genom att jämföra två på varandra följande 10-årsperioder och avstämningar av i vilken utsträckning samma tjärnar var bebodda under minst ett år under båda 10-årsperioderna.

Tillgången till informationen från tidigare år varierar mellan de undersökta tjärnarna; en del av dem har kontrollerats ganska regelbundet (ibland årligen) under de senaste årtiondena, medan andra har besökts mera sporadiskt. Det finns alltså en risk att ett fåtal tjärnar har felaktigt bedömts sakna häckande smålommar, speciellt för perioden före 1979. Bedömningar och slutsatser grundar sig således inte på ett helt perfekt underlag utan på "bästa tillängliga" information.

"Tjärnar med en lång häckningskontinuitet" definierades som sådana där häckning fastställts före 1979 och därefter under varje 10-årsperiod samt under perioden 2009-2011. De jämfördes med övriga tjärnar med avseende på häckningsutfallet och procentandelen år med häckning, men med följande restriktioner i urvalet: Endast tjärnar med tillräcklig information för att möjliggöra en bedömning om häckning sannolikt hade ägt rum för minst tio år under perioden 1994-2011, och med information om häckningsutfallet under minst fem år under samma period, ingick i jämförelsen. Det genomsnittliga häckningsutfallet beräknades som medelantalet stora ungar per par och år, enligt den metod som används generellt inom Projekt LOM (för detaljer, se bilaga 1 i Eriksson 2010). Referensperioden 1994-2011 betingades av att inventeringarna inom Projekt LOM påbörjades 1994, och att det fanns bättre tillgång på användbar information fr.o.m. detta år, jämfört med tidigare.

\section{Resultat}

Förekomsten av häckande smålommar 2009, 2010 och/eller 2011 i relation till uppgifter om häckningar under tidigare år fördelade sig enligt följande för de 149 undersökta tjärnarna: 35 tjärnar med 
Tabell 1. Detaljresultat för sydvästra Sverige.

Detailed results for south-western Sweden.

a) Häckningar före 2009 vid de 35 tjärnarna med fastställd häckning 2009-11.

- 23 tjärnar (66 \%) med häckning under minst ett år under perioden 1999-2008.

- 4 tjärnar (11\%) med häckning under minst ett år under perioden 1989-1998 men utan uppgifter om häckning därefter.

- 2 tjärnar (6 \%) med häckning minst ett år under perioden 1979-1988 men utan uppgift om häckning därefter.

- 6 tjärnar (17\%) utan uppgifter om häckning före 2009.

b) Tidigast kända häckning vid de 35 tjärnarna med häckning 2009-2011:

- 6 tjärnar (17\%) med tidigaste kända häckning under perioden 1999-2008.

- 6 tjärnar (17\%) med tidigaste kända häckning under perioden 1989-1998.

- 6 tjärnar (17\%) med tidigaste kända häckning under perioden 1979-1988.

- 11 tjärnar (31\%) med tidigaste kända häckning före $1979 ; 8$ (23\%) av dem med en obruten häckningskontinuitet från tiden före 1979 t.o.m. perioden 2009-2012.

- 6 tjärnar (17\%) utan uppgifter om tidigare häckning.

c) Häckningar före 2009 vid de 19 tjärnarna med observation av smålom men ingen fastställd häckning 2009-11.

- 6 tjärnar (32\%) med häckning under minst ett år under perioden 1999-2008.

- 2 tjärnar (11\%) med häckning under minst ett år under perioden 1989-1998 men utan uppgifter om häckning därefter.

- 2 tjärnar (11\%) med häckning under minst ett år under perioden 1979-1988 men utan uppgifter om häckning därefter.

- 1 tjärn (5\%) med häckning under minst ett år före 1979 men utan uppgifter om häckning därefter.

- 8 tjärnar (42\%) utan uppgifter om häckning före 2009. a) Breeding before 2009 at the 35 tarns with breeding confirmed 2009-11.

- 23 tarns (66\%) with breeding confirmed at least once during the period 1999-2008.

- 4 tarns (11\%) with breeding confirmed at least once during the period 1989-1998 but not thereafter.

- 2 tarns (6\%) with breeding confirmed at least once during the period 1979-1988 but not thereafter.

- 6 tarns $(17 \%)$ without any information about breeding before 2009.

b) Earliest known breeding at the 35 tarns with breeding confirmed 2009-2011

- 6 tarns (17\%) with the earliest confirmed breeding during the period 1999-2008.

- 6 tarns (17\%) with the earliest confirmed breeding during the period 1989-1998.

- 6 tarns $(17 \%)$ with the earliest confirmed breeding during the period 1979-1998.

- 11 tarns (31\%) with the earliest confirmed breeding before 1979; eight (23\%) of them with a long breeding continuity from before 1979 until 2009-11.

- 6 tarns (17\%) without any information about previous breeding.

c) Breeding before 2009 at the 19 tarns with records of Red-throated Loon but no breeding confirmed 200911

- 6 tarns (32\%) with breeding at least once during the period 1999-2008.

- 2 tarns (11\%) with breeding at least once during 1989-1998 but no information about breeding after that

- 2 tarns $(11 \%)$ with breeding at least once during 1979-1988 but no information about breeding after that.

- 1 tarn (5\%) with breeding at least once before 1979 but no information after that.

- 8 tarns (42\%) without any information about breeding before 2009. 
häckning minst ett år under perioden 2009-2011 (dessutom noterades under fältarbetet smålommar i ytterligare 19 tjärnar), 50 tjärnar utan fastställd häckning under perioden 2009-2011, men med uppgifter om häckning tidigare år, och 64 tjärnar utan fastställd häckning under perioden 2009-2011 och utan uppgifter om häckning tidigare år.

Inventeringsresultatet antyder att det förekommer både åter- och nyetableringar. Bland de 35 tjärnarna med häckning minst ett år under perioden 2009-2011 noterades två tredjedelar av de häckande paren i tjärnar som nyttjats för häckning minst ett år eller (i flertalet fall) flera år under den föregående 10-årsperioden, medan sex par (17\%) häckade vid tjärnar dit smålommen bedömts ha återkommit efter att de stått tomma under ett antal år. Ytterligare sex par häckade vid tjärnar utan information om tidigare häckningar överhuvudtaget (Tabell 1a).

Den tidigast kända häckningen inträffade före 1979 för närmare en tredjedel av tjärnarna, och nästan en fjärdedel hade därefter nyttjats regelbundet av häckande smålommar under den senaste 30-årsperioden (Tabell 1b). Dessa tjärnar representerar en lång häckningstradition över flera decennier i några fall. $\AA$ andra sidan skedde en annan tredjedel av häckningarna i tjärnar utan uppgifter om tidigare häckningar eller med den tidigast kända häckningen under den närmast föregående 10 -årsperioden. För flertalet av dessa bedömer vi att det har varit fråga om nyetableringar.

För de 19 tjärnarna där smålom sågs under fältarbetet 2009, 2010 och/eller 2011 utan att häckning kunde fastställas, avsåg över hälften av observationerna tjärnar med tidigare uppgifter om häckningar. För en tredjedel av dem gällde att häckning hade noterats under minst ett år under den senaste 10-årsperioden (Tabell 1c).

Totala antalet tjärnar med häckning fastställd för minst ett år under de olika 10-årsperioderna samt för perioden 2009-2012 låg på en ganska konstant

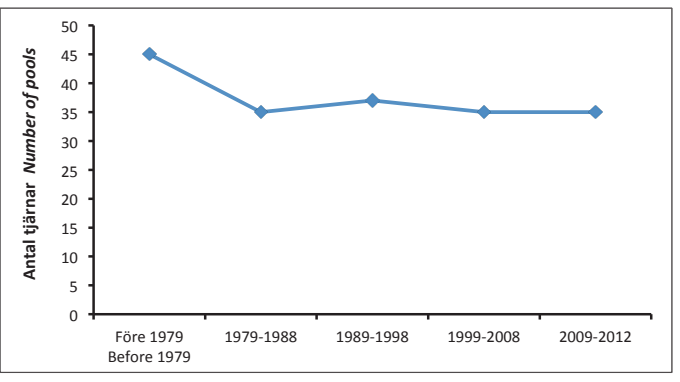

Figur 2. Antalet tjärnar med fastställd häckning i sydvästra Sverige.

Number of tarns with confirmed breeding in south-western Sweden.

nivå på 35-37 tjärnar, medan det ackumulerade antalet före 1979 var högre, 45 tjärnar (Figur 2). Det högre antalet före 1979 kan möjligen återspegla en större häckningspopulation under årtiondena närmast före 1980 jämfört med senare, men kan också förklaras av att uppgifter ackumulerats över en lägre tid före 1979. Den till synes stabila nivån efter 1979 är mer svårtolkad och resultatet utesluter inte en fortsatt minskning. En reell minskning kan ha mörkats av en ökad fältornitologisk verksamhet under de senaste årtiondena och därmed ökade chanser att hitta häckande smålommar.

Däremot har det skett en omfördelning av häckningstjärnarna under den senaste 30-årsperioden. Materialet möjliggjorde två jämförelser mellan två på varandra följande 10-årsperioder. Från en 10-årsperiod till nästa övergavs ungefär $30 \%$ av tjärnarna. Förlusterna tycks ha kompenserats genom åter- och nyetableringar, med reservation för att enstaka nyupptäckta lokaler kan ha hyst smålomspar som häckat men förblivit oupptäckta sedan längre tid tillbaka (Tabell 2).

Jämförelsen mellan tjärnar med lång häckningskontinuitet och övriga tjärnar visade att det årliga häckningsutfallet låg på samma nivå för par i båda

Tabell 2. Omfördelningen av häckande smålommar mellan två på varandra följande tioårsperioder i sydvästra Sverige.

Table 2. The redistribution of breeding Red-throated Loon between two consecutive 10-year periods in southwestern Sweden.

\begin{tabular}{lcccc}
\hline Period & Antal tjärnar & \multicolumn{3}{c}{$\begin{array}{c}\text { Fördelningen under den påföljande perioden, antal tjärnar } \\
\text { Distribution during the following period, number of tarns }\end{array}$} \\
\cline { 3 - 5 } Period & Number of & Häckning & Ej häckning & Ny- eller återetableringar \\
& tarns & Breeding & No breeding & New establishments or reoccupations \\
\hline $1979-88$ & 35 & $23(66 \%)$ & $12(34 \%)$ & 14 \\
$1989-98$ & 37 & $27(73 \%)$ & $10(27 \%)$ & 8 \\
\hline
\end{tabular}


Tabell 3. Jämförelse mellan tjärnar med lång häckningskontinuitet och övriga tjärnar i sydvästra Sverige, 19942011.

Comparison between tarns with a long breeding continuity and other tarns in south-western Sweden, 1994-2011.

\begin{tabular}{lcccccc}
\hline & $\begin{array}{c}\text { Lång kontinuitet } \\
\text { Long continuity }\end{array}$ & $\begin{array}{c}\text { Övriga } \\
\text { Other }\end{array}$ & \multicolumn{2}{c}{$\begin{array}{c}\text { Mann-Whitney } \\
\text { U-test }\end{array}$} \\
\cline { 2 - 7 } & $\begin{array}{l}\text { Medel- } \\
\text { värde } \\
\text { Mean }\end{array}$ & $\mathrm{N}$ & $\begin{array}{c}\text { Medel } \\
\text { värde } \\
\text { Mean }\end{array}$ & $\mathrm{N}$ & $\mathrm{U}$ & $\begin{array}{c}\mathrm{p} \\
\text { tvåsidigt } \\
\text { two-tailed }\end{array}$ \\
\hline $\begin{array}{l}\text { \%-andel år med häckning } \\
\% \text { years with breeding }\end{array}$ & $74 \%$ & 7 & $35 \%$ & 21 & 20 & $=0,005$ \\
$\begin{array}{l}\text { Medelantal stora ungar } \\
\text { per par och år } \\
\begin{array}{l}\text { Mean number of large chicks } \\
\text { per pair and year }\end{array}\end{array}$ & 0,87 & 6 & 0,95 & 8 & 20,5 & $\begin{array}{c}\text { ej sign. } \\
\text { N.S. }\end{array}$ \\
\hline
\end{tabular}

kategorierna av tjärnar. Däremot nyttjades tjärnarna med en lång häckningstradition mera frekvent; i genomsnitt under tre av fyra år, jämfört med häckning ungefär vart tredje år för de övriga (Tabell 3). Även om medelantalet ungar per påbörjad häckning inte särskiljde sig, torde antalet ungar ändå ha blivit större för tjärnarna med en lång häckningstradition sett över en period på ett antal år, eftersom dessa tjärnar nyttjats $\mathrm{i}$ genomsnitt dubbelt så ofta för häckning.

\section{Dalsland}

Undersökningen omfattade landskapet Dalsland, eller mera exakt Bengtsfors, Dals-Eds, Färgelanda, Melleruds och Åmåls kommuner samt nordvästra delen av Vänersborgs kommun.

1944-1962 genomförde Nils-Gerhard Karvik en inventering av vertebratfaunan i landskapet. Projekt LOM har kunnat ta del av inskannade kopior av de originalanteckningar som låg till grund för hans avhandling i ämnet (Karvik 1964). På så vis blev det möjligt att jämföra förekomsten av smålom i landskapet över ett halvsekel genom att ställa Karviks material för 18-årsperionden 1944-1962 mot information som i huvudsak samlats in av Projekt LOM under perioden 1994-2012, som likaledes omfattade 18 år.

Under de år som fältarbetet pågick besökte Karvik alla delar av landskapet, och det framgår av anteckningarna att han intervjuade och samtalade med flera personer. En del av uppgifterna var således av andrahandskaraktär redan när Karvik sammanställde sitt arbete. Vi bedömer att Karvik genom sitt eget fältarbete och tillsammans med sina sagesmän och medhjälpare täckte upp en stor del av alla tänkbara smålomslokaler i Dalsland.

\section{Metodik}

För perioden 1944-1962, och på basis av information i Karviks originalanteckningar, har alla lokaler där han gjort noteringar om fastställda häckningsplatser (bo, ägg eller ungar), eller där han har bedömt att det varit fråga om troliga häckningsplatser, räknats in som häckningslokaler för smålom.

För de lokaler som ingår i undersökningen för perioden 1994-2012 gäller att de under minst ett år skall ha besökts vid minst två tillfällen; med det första besöket kring den 1 juni ( \pm två veckor) och det andra besöket den 15 juli ( \pm två veckor), dvs. samma metod som tillämpades för sydvästra Sverige och således en mer strikt bedömning än vad som varit möjlig vid genomgången av Karviks anteckningar för perioden 1944-1962.

\section{Resultat}

För perioden 1944-1962 bedömde Karvik att det häckade ungefär 40 smålomspar i Dalsland, och på en karta redovisade han 39 häckningsplatser (Karvik 1964, figur 30). Efter genomgången av hans originalanteckningar bör antalet lokaler med trovärdiga uppgifter om häckning emellertid justeras, som följer: Tre lokaler ligger strax utanför landskapet (1 i Bohuslän, 2 i Värmland). Två lokaluppgifter avser förhållandevis stora sjöar, där det är mera troligt att det rör sig om fiskevatten. Fem lokaler har vid bedömningen av Karviks egna anteckningar ansetts som tveksamma. Två lokaler, som inte redovisats på kartan, bör med ledning av anteckningarna bedömas som trovärdiga häckningsplatser.

Den nya granskningen har alltså lett fram till att trovärdiga uppgifter om häckning föreligger från minst 31 lokaler under perioden 1944-1962, 
inklusive en lokal med två häckande par, alltså totalt 32 par. 21 av dessa lokaler har även besökts under minst ett år under perioden 1994-2012 och häckning kunde fastställas på fem $(24 \%)$ av dessa platser. För $76 \%$ av de lokaler som redovisades av Karvik har vi alltså inte kunnat fastställa någon häckning ett halvsekel senare.

Under perioden 1994-2012 har totalt 56 tjärnar och småsjöar inventerats under minst ett år (ofta flera), varav 21 tjärnar även ingick i Karviks material. Häckning under ett eller flera år har fastställts för 29 av lokalerna, med ett par på varje lokal utom en där som mest tre par noterats under samman häckningssäsong, alltså totalt 31 par. Man bör emellertid beakta att mer strikta kriterier tillämpats för perioden 1994-2012; räknar man in tre tjärnar med förekomst av ett stationärt par under minst ett år, utan att häckning kunnat fastställas, blir det totalt 32 lokaler med 34 par.

En rent numerär jämförelse hamnar alltså på ungefär samma nivå för både antalet tjärnar med häckning och antalet par för perioderna 1944-1962 och 1994-2011. Men rimligtvis har den fältornitologiska aktiviteten varit större under perioden 1994-2012 än 50 år tidigare, och förutsättningarna att hitta flertalet av häckningsplatserna i landskapet torde alltså ha varit bättre. Därför kan man inte utesluta en minskning i smålomsbeståndet sedan mitten av 1900-talet.

Det har också skett en geografisk omfördelning av häckningsplatserna. Karvik noterade smålommar vid bara fem (17\%) av de 29 lokalerna med häckning under ett eller flera år under perioden 1994-2012. Vidare var en häckningstjärn, där Karvik bedömde att smålommen hade försvunnit, bebodd under perioden 1994-2012.

\section{Hagfors kommun i Värmland}

Under häckningssäsongen 2010 återinventerade Wermlands Ornitologiska Förening huvuddelen av de lokaler som besöktes inom ramen för en kommuntäckande undersökning 1995 (Borgström 1996). Inventeringen omfattade östra delen av Hagfors kommun eller mera exakt de delar av de topografiska kartbladen 11D NO, 12D SO och 12D NO som ligger inom kommunen och svarande mot ungefär $60 \%$ av kommunens yta. Fältarbetet omfattade alla tjärnar där häckning kunde fastställas vid inventeringen 1995 i den aktuella delen av kommunen, plus ytterligare ett antal. En mer detaljerad sammanställning har publicerats i Wermlands Ornitologiska Förenings tidsskrift Värmlandsornitologen (Schütt \& Westerlund 2010).

\section{Metodik}

Fältarbetet 2010 gjordes med samma metod som inom de ordinarie inventeringarna i Projekt LOM. Ett första besök gjordes under perioden 25 maj-29 juni, i först hand för eftersök av ruvande fåglar och med huvuddelen av besöken under sista veckan av maj eller början-mitten av juni (motsvarade besöket den 1 juni \pm två veckor för sydvästra Sverige och Dalsland). Totalt besöktes 306 tjärnar, men flera av dem gallrades bort efter att de bedömts som mindre attraktiva. För återstående 156 tjärnar gjordes ett andra besök under perioden 5 juli-3 augusti i samma tidsordning som det första besöket, och i första hand för eftersök av ungar. Huvuddelen av besöken gjordes under mitten av slutet av juli (motsvarande omkring 15 juli \pm två veckor för sydvästra Sverige och Dalsland). För några av tjärnarna gjordes ytterligare något eller några besök för uppföljning av ungarnas överlevnad. Dessutom kompletterades fältarbetet med 20 tjärnar som inte besöktes under maj-juni.

Inventeringen 1995 utfördes med ett besök under perioden 29 juni-10 augusti, dvs. resultaten från 1995 är jämförbara med de från perioden 5 juli-3 augusti i 2010 års inventering.

\section{Resultat}

Inventeringsresultatet tyder på att det både skett en minskning av antalet häckande par och omflyttningar mellan tjärnarna under 15 -årsperioden mellan 1995 och 2010.

Både 1995 och 2010 kunde häckning av smålom fastställas vid 33 av de undersökta tjärnarna. År 1995 gjordes emellertid inget fältarbete förrän under perioden 29 juni-10 augusti, varför ett antal påbörjade häckningar som avbrutits säkerligen har missats. Hade man även 1995 gjort ett första besök under maj-juni skulle antalet tjärnar med fastställd häckning rimligtvis blivit fler. Jämförs i stället antalet tjärnar med häckning under den andra inventeringsomgången 2010 med inventeringen 1995 finner man att antalet tjärnar där häckning kunnat fastställas genom notering av ungar var 33 för 1995 och 26 för 2010, dvs. en minskning med 21\%.

För 10 av de undersökta tjärnarna kunde häckning fastställas både 1995 och 2010. Detta betyder att $30 \%$ av de 33 tjärnarna där ungar noterades 1995 var bebodda även 2010 och att $38 \%$ av de 26 tjärnarna med ungar 2010 vara bebodda även 1995.

Ser man på resultatet mer $\mathrm{i}$ detalj finner man dessutom att minskningen har varit koncentrerad till kommunens norra och mellersta delar (kart- 
bladen 12D SO och 12D NO), medan det skett en ökning i den södra kommundelen (kartbladet 11D NO). Antalet tjärnar med fastställd häckning minskade från 26 till 16 par (-38\%) i den norra delen, medan antalet ökade från 7 till 10 tjärnar med fastställd häckning $(+43 \%)$ i den södra.

\section{Diskussion}

Omflyttning mellan häckningsplatser och trender $i$ det häckande beståndets storlek

Återbesöken av smålomslokaler med fynddata som ligger något eller några årtionden tillbaka $\mathrm{i}$ tiden i tre skilda områden i landets södra och mellersta delar visar entydigt att det sker en kontinuerlig omflyttning mellan olika häckningstjärnar. Resultaten från sydvästra Sverige antyder att ungefär $30 \%$ av häckningstjärnarna överges under en 10-årsperiod, medan närmare en fjärdedel torde vara "gamla" häckningslokaler som nyttjats mer eller mindre regelbundet av häckande smålommar under en period på över 30 år.

Förlusten av häckningstjärnar har till stor del kompenserats genom ny- eller återetableringar. Den minskning som flera inventerare har rapporterat om torde åtminstone till en del kunna förklaras av att smålommarna har flyttat till andra tjärnar som man inte har besökt under fältarbetet. Med hänvisning till fältarbeten i Malungs kommun i Dalarna under en 10-årsperiod (1991-2000; Dahlén \& Eriksson 2002), kan man dessutom sluta sig till att smålommarna är mer benägna att överge en häckningsplats efter en misslyckad häckning och att predation torde vara den viktigaste orsaken till misslyckade häckningar, men också att tjärnarna ibland återbesätts efter några år.

I sydvästra Sverige har antalet tjärnar med fastställd häckning legat på ungefär samma nivå från omkring 1980 fram till idag, och i Dalsland kunde häckning fastställas eller bedömas som trolig för ungefär lika många tjärnar under perioden 1994 2012 som ett halvsekel tidigare. Men samtidigt har den fältornitologiska aktiviteten ökat under senare årtionden och förutsättningarna för att lokalisera tidigare oupptäckta häckningsplatser har sannolikt ökat. Resultaten för sydvästra Sverige och Dalsland blir därför en aning svårbedömbara, och det kan inte uteslutas att det har skett en fortlöpande tillbakagång under mitten och slutet av 1900-talet och därefter.

I Hagfors kommun kunde man mera entydigt fastställa en minskning av antalet häckande par från mitten av 1990-talet till 2010 (Schütt \& Wes- terlund 2010). I den västra grannkommunen Sunne noterades en minskning från 30-35 par vid mitten av 1980-talet till 25 par 2005 (Schützer \& Schütt 2005), alltså en tillbakagång av ungefär samma storleksordning som i Hagfors.

\section{Smålomsbeståndens storlek $i$ sydvästra Sverige och i Dalsland}

De mest aktuella skattningarna av olika fågelarters numerär på nationell och regional nivå har sammanställts i boken "Fåglarna i Sverige - antal och förekomst" (Ottosson et al. 2012). För smålommen i sydvästra Sverige redovisas skattningar för landskapen Västergötland och Halland på 35 resp. 12 par (Ottosson et al. 2012, sid. 111), vilka i sin tur bygger på bedömningar på 25-40 resp. 10-15 par av Projekt LOM (Eriksson 2010, sid. 43). För Västergötland bortfaller uppskattningsvis fem par som häckar utanför det undersökningsområde som avgränsats i den här studien, och då återstår ett häckande bestånd inom intervallet 30-45 par. Denna siffra kan ställas i relation till att häckningar kunde fastställas på 35 platser under perioden 2009-2011. För Dalsland redovisas 25 par (Ottosson et al. 2012, 25-30 par i Eriksson 2010), vilket kan relateras till att häckning fastställdes på 29 platser under minst ett år under perioden 1994-2012.

Man kan inte utan eftertanke sätta likhetstecken mellan antalet häckningsplatser och antalet häckande par. För sydvästra Sverige och Dalsland har bedömningarna gjorts på basis av antalet tjärnar med fastställda häckningar över perioder på flera år, och vi har visat att det förekommer en omflyttning mellan olika häckningsplatser. Därför kan man inte utesluta att ett och samma par har häckat vid olika tjärnar under den tidsperiod bedömningen omfattar. Likställer man antalet tjärnar med fastställd häckning med antalet häckande par kan det alltså bli en överskattning av beståndets storlek. För Hagfors kommun kan man emellertid bortse från den här problematiken $\mathrm{i}$ just den här studien, eftersom jämförelsen bygger på inventeringar under två enstaka år, 1995 och 2010.

Det kan också finnas ett mörkertal av häckande smålomspar som undgått upptäckt, och en kvittens på detta är att Projekt LOM har informerats om två inte tidigare kända häckningsplatser i sydvästra Sverige efter att fältarbetet avslutats 2011. Slutligen förekommer det i sällsynta fall att mer än ett par häckar vid samma tjärn, eller att flera par häckar i angränsande myrgölar på samma myrkomplex.

Trots reservationerna kan man konstatera att antalet häckningsplatser som lokaliserats un- 
der inventeringsarbetet i sydvästra Sverige och i Dalsland ligger inom de intervallskattningar av de häckande beståndens storlek som tidigare har redovisats av Projekt LOM (Eriksson 2010) och i "Fåglarna i Sverige - antal och förekomst" (Ottosson et al. 2012).

\section{Naturvårdstillämpningar}

Ett viktigt resultat är att tjärnar med en lång häckningskontinuitet, dvs. att de har nyttjats mer eller mindre regelbundet av häckande smålommar under flera årtionden, totalt torde bidra med en förhållandevis stor del av ungproduktionen, sett över en längre tidsperiod. Visserligen skiljde sig inte det årliga häckningsutfallet för smålomspar häckande i tjärnar med en lång häckningstradition (över 30 år) från de övriga häckningstjärnarna, men däremot nyttjades de betydligt oftare för häckning; i genomsnitt tre av fyra år jämfört med ungefär vart tredje år för övriga tjärnar (Tabell 3).

De par som häckar i tjärnar med en lång tradition torde alltså spela en stor roll for smålomsbeståndets rekrytering och fortlevnad. Det är därför viktigt att dessa tjärnar lokaliseras och beaktas i det fortlöpande naturvårdsarbetet. Generella rekommendationer om att man bör undvika att placera vindkraftverk inom närområdet (upptill $1 \mathrm{~km}$ ) kring tjärnarna, liksom i flygstråken till kringliggande fiskevatten (Eriksson 2012, Bright et al. 2006, sid. 29-34), måste speciellt beaktas för häckningstjärnar som kan antas ha nyttjats under lång tid. Man bör även undvika att bygga skogsbilvägar i närheten av tjärnarna och undvika störande verksamheter, såsom avverkningar under häckningstid, i närheten av dem. Tjärnarna med en lång häckningskontinuitet skall självfallet också beaktas vid planeringen av t.ex. anläggningar för friluftslivet, såsom vandringsleder, rastplatser och vindskydd, och de bör inte bli föremål för utsättning av fisk eller upplåtas för sportfiske.

En annan aspekt är att inventeringar inför olika typer av exploateringar, t.ex. för vindkraftsparker, ofta bara omfattar en enda häckningssäsong. Eftersom det är mer regel än undantag att häckningstjärnar, även de som nyttjats kontinuerligt i ett längre tidsperspektiv, kan vara obebodda enstaka år finns det alltså en risk att man missar viktiga häckningsplatser. Därför måste inventeringar och miljökonsekvensbeskrivningar kompletteras med uppgifter om häckningsförekomster under tidigare år och potentiella häckningstjärnar, och sådan information skall finnas med i beslutsunderlagen.

\section{Lärdomar inför det fortsatta inventeringsarbetet}

Uppgifter om att smålommen har försvunnit på skilda håll kan alltså till viss del kopplas till den dynamik som normalt tycks finnas inom ramen för ett mönster där häckningsplatser överges, nyetableringar sker på annat håll och att gamla häckningsplatser återbesätts efter att ha stått tomma några år. Långsiktiga inventeringar av häckande smålommar måste alltså innefatta eftersök i småsjöar och tjärnar utan tidigare information om arten och återbesök på lokaler med gamla fynduppgifter, för att säkra att man täcker in tillräckligt många fastställda häckningar för meningsfulla bedömningar av häckningsutfallet och beståndsutvecklingen.

Detta kan emellertid te sig som en övermäktig uppgift då kartbilden även inom ett ganska begränsat område ofta kan innehålla ett stort antal (ibland något eller några 100-tal) småsjöar och tjärnar $(<$ 1 ha). Sökarbetet kan i någon mån underlättas om man koncentrerar fältarbetet till tjärnar som med ledning av kartor och/eller flygbilder bedöms ha välutvecklade gungflystränder med lämpliga boplatser, och till närområdet och upptill ungefär 8-9 km kring kända fiskevatten (det tycks finnas ett tröskelvärde på 8-9 km för avståndet mellan boplatser och fiskevatten, även om avståndet för enstaka boplatser är längre; Eriksson 2010, sid. 52).

Parallellt eller alternativt kan man även arbeta med utgångspunkt från kända fiskevatten, genom att ta ut flygriktningarna för smålommar som lämnar sjön med bytesfisk och söka upp tänkbara småsjöar och tjärnar i den riktningen. Om samma par nyttjar två olika fiskevatten kan man genom triangulering ibland begränsa de tänkbara häckningsplatserna till bara ett fåtal.

Med detta arbetssätt frångår man visserligen principen att välja ut tjärnarna som blir föremål för besök på strikt slumpmässiga grunder. Denna nackdel får emellertid vägas mot behovet att på ett någorlunda arbetseffektivt sätt långsiktigt söka upp ett tillräckligt stort antal par (och lokaler) för att undvika att underlaget på sikt blir för litet för meningsfulla bedömningar av häckningsutfallet och beståndsutvecklingen.

\section{Tack}

I sydvästra Sverige har Claes-Göran Ahlgren, Owe Arnoldsson, Anders Ericsson, Lars Gerre, Gunnar Gustafsson, Dan Johansson, Sigvard Lundgren, Hans Nilsson, Claes Persson, Ronny Fallberg och Peter Wredin medverkat i fältarbetet. Fältarbetet i Hagfors kommun 2010 har organiserats av Lars 
Schütt och Lars-Ola Westerlund, och dessutom har Mikael Karlow deltagit. Genom Hans Alexanderssons förmedling har vi kunnat ta del av Nils-Gerhards Karviks handskrivna anteckningar från hans fältarbete i Dalsland från perioden 1944-1962. Anteckningarna finns arkiverade på Vänersborgs museum. Jämförelsen mellan 1944-1962 och 19942012 hade inte varit möjlig utan ett träget fältarbete i delar av Dalsland av bland andra Sture Orrhult, Bengt Wiklund, Kent Nilsson, Johnny Björn Hansen, Åke Gustavsson och Kent-Åke Gustavsson under perioden 1994-2012. För sydvästra Sverige och Dalsland har kompletterande information också hämtats från Artportalen/Svalan.

För fältarbetet har Projekt LOM fått ett bidrag från Alvins Fond (Naturvårdsverket dnr 433-864108, enligt protokollsutdrag, 2009-02-26). För arbetet i Hagfors kommun har även Länsstyrelsen i Värmlands län bidragit ekonomiskt, och för arbetet i sydvästra Sverige har Ulricehamns kommun bidragit med reskostnader för inventeringar av lokaler belägna i kommunen.

\section{Referenser}

Borgström, E. 1996. Smålommen i Hagfors kommun 1995. Värmlandsornitologen 24: 45-50.

Bright, J.A., Langston, R.H.W., Bullman, R., Evans, R.J., Gardner, S., Pearce-Higgins, J. \& Wilson, E. 2006. Bird sensitivity map to provide locational guidance for onshore windfarms in Scotland. RSBP Research Report No. 20.

Dahlén, B. \& Eriksson, M.O.G. 2002. Smålommens Gavia stellata häckningsframgång i artens svenska kärnområde. Ornis Svecica 12: 1-33.

Eriksson, M.O.G. 2010. Storlommen och smålommen i Sverige - populationsstatus, hotbild och förvaltning. Sveriges Ornitologiska Förening, Stockholm och Svenska LOMföreningen / Projekt LOM, Göteborg; http://www.projekt-lom.com/Lommar $\% 20$ status $\% 20$ hotbild $\% 20$ etc $\% 20$ 2010.pdf

Eriksson, M.O.G. 2012. Projekt Lom 2011. I: SOF 2012. Fågelåret 2011, sid. 45-55. Sveriges Ornitologiska Förening, Stockholm.

Eriksson, M.O.G., Arvidsson, B.L. \& Johansson, I. 1988. Habitatkaraktärer hos häckningssjöar för smålom Gavia stellata i sydvästra Sverige. Vår Fågelvärld 47: 123-132.

Eriksson, M.O.G. \& Johansson, I. 1997. Smålommen Gavia stellata i sydvästra Sverige - beståndsutveckling och häckningsframgång. Ornis Svecica 7: 1-10.

Karvik, N-G. 1964. The terrestrial vertebrates of Dalsland in southwestern Sweden. A zoogeographic study. Acta Vertebratica 3, nummer 1: 1-239.

Lindström, Å. \& Green, M. 2013. Övervakning av fåglarnas populationsutveckling. Arsrapport för 2012. Ekologiska institutionen, Lunds universitet, Lund.

Ottosson, U., Ottvall, R., Elmberg, J, Green, M, Gustafsson, R., Haas, F., Holmqvist, N., Lindström, Å., Nilsson, L., Svensson, M, Svensson, S. \& Tjernberg, M, 2012. Fåg- larna i Sverige - antal och förekomst. Sveriges Ornitologiska Förening, Halmstad.

Ottvall, R., Edenius, L., Elmberg, J., Engström, H., Green, M., Holmqvist, N., Lindström, Å., Tjernberg, M. \& Pärt, T. 2008. Populationstrender för fågelarter som häckar i Sverige. Naturvårdsverket Rapport 5813.

Schütt, L. \& Westerlund, L.-O. 2010. Smålommen Gavia stellata i Hagfors kommun 2010 - samt jämförelser med tidigare inventeringar. Värmlandsornitologen 38: 51-67.

Schützer, J. \& Schütt, L. 2005. Smålommen Gavia stellata i Sunne kommun 2005 - en uppföljning av en 20 år tidigare gjord inventering. Värmlandsornitologen 33: 65-72.

Svensson, S., Svensson, M. \& Tjernberg, M. 1999. Svensk fågelatlas. Vår Fågelvärld, supplement 31. Sveriges Ornitologiska Förening, Stockholm.

\section{Summary}

Red-throated Loon Gavia stellata has been subject of bird conservation for a long time, with several potential threats and concern of low recruitment (e.g. Eriksson 2010). In Sweden, results from nation-wide and voluntary-based surveys (Projekt LOM, e.g. Eriksson 2012), have indicated that many breeding sites used in the mid-1990s have been abandoned, but the surveys do not clarify if this loss should be ascribed to a population decline or movements to other breeding sites. With this background, Projekt LOM initiated searches for breeding pairs at potential sites with no previous information about any occurrence of Red-throated Loon and checked abandoned sites that had not been visited for some years. The main questions were: Can any decline in the population size in South Sweden be verified? Has the disappearance from breeding tarns been compensated for by establishing at new sites or reoccupation of sites used in the past?

The field-work was done in three study areas (Figure 1): (1) South-western Sweden, basically the southern part of Västra Götaland County and the northern and central parts of Halland County. This area has also been covered in previous studies (Eriksson et al. 1988, Eriksson \& Johansson 1997). The field-work was done during 2009-2011. (2) Province of Dalsland, i.e. the north-western parts of Västra Götaland County, where surveys from 1944-1962 (Karvik 1964) were compared with work done 50 years later during 1994-2012. (3) Hagfors Municipality, where a fully covering survey done in 1995 (Borgström 1996) was partly repeated in 2010. 
South-western Sweden

Material and methods

The field-work included 149 small lakes or tarns, and about half of them were known to have harboured breeding Red-throated Loons in the past.

As a minimum, the sites were visited twice during at least one of the years 2009, 2010 and/ or 2011. The first visit was done around 1 June ( \pm 2 weeks) in order to search for pairs and incubating birds, and the second visit around 15 July $( \pm 2$ weeks) in order to search for chicks. Sites where no Red-throated Loons were seen at the first visit were nevertheless checked a second time, in order to reduce the risk of overlooking incubating birds, or late breeding attempts. Further visits were done, if needed, in order to follow up initiated breeding or the survival of chicks. The field checks followed the same methodology as used in the ordinary surveys done by Projekt LOM (see Annex 1 in Eriksson 2010 for details).

The result for the period 2009-2011 was related to the outcome of previous surveys and if breeding had been verified for at least one year before 1979 and/or during each one of the 10-year periods of 1979-1988, 1989-1998 and 1999-2008. The data for individual sites varied; some of them were checked regularly (sometimes annually) during recent decades, whereas other tarns were visited only sporadically. There is thus a risk that some tarns have been erroneously classified as not harbouring any breeding pairs, especially for the period before 1979. So the conclusions from this study are based on the best available information rather than perfect data.

Tarns where breeding was confirmed for at least one year before 1979 and thereafter regularly during each 10-year period as well as during 20092011 were classified as "tarns with a long breeding continuity". They were compared with the other tarns with reference to breeding success and the percentage of years when breeding was confirmed; with the restrictions that only tarns with information that allowed for an accurate assessment if breeding had occurred during at least ten years during 1994-2011 and with reliable data on the breeding success during at least five years, were included. The average breeding success, in terms of the mean number of large chicks per pair and year, was assessed following the methodology of Projekt LOM (Annex 1 in Eriksson 2010). The reference period of 1994-2011 was related to the start of Projekt LOM and more reliable information than before 1994.
Results

The 149 tarns included in the study were distributed as follows: 35 tarns with breeding confirmed for at least one year during 2009-2011 (in addition, Red-throated Loons were recorded at another 19 sites), 50 tarns without any confirmation of breeding during 2009-2011, but with breeding confirmed for at least one year before 2009, and 64 tarns without any confirmation of breeding during 2009-2011 or earlier.

Among the 35 tarns with breeding at least once during 2009-2011, two thirds of them had been used at least once during the previous period of 1999-2008, whereas breeding birds most likely had returned to six tarns $(17 \%)$ after the sites had been abandoned for some years. Another six pairs bred at tarns without any information about previous breeding (Table 1a).

The first breeding record was before 1979 for about one third of the tarns, and almost one quarter had since then been regularly used during the last 30 years (Table $1 \mathrm{~b}$ ). These tarns represent a long breeding tradition, over several decades in some cases. Another third of the pairs bred at tarns with no previous information about breeding or where the first breeding was confirmed only during the previous ten years; assumed to represent establishments at new breeding sites in most cases.

For the 19 tarns with records of Red-throated Loons during 2009-2011, but without any confirmed breeding, more than half of the observations were at tarns with previous information about breeding birds. For one third of them, breeding had been confirmed during at least one year during the preceding 10-year period (Table 1c).

The number of tarns where breeding was confirmed for at least one year during each one of the 10-year periods and during 2009-2011 was at a constant level of 35-37 tarns from 1979 onwards, but the total number accumulated before 1979 was higher, 45 tarns (Figure 2). This may reflect a larger breeding population during the decades before 1980 than later, or simply that a higher number of tarns with information about breeding had accumulated over a longer time before 1979 than after. However, the seemingly constant number of occupied tarns after 1979 may nevertheless indicate a continuous decline, having in mind the increased ornithological activity during recent decades and thus an increased probability to find breeding pairs.

The survey revealed a substantial redistribution of occupied tarns. During a period of ten years, around $30 \%$ of the tarns were abandoned, but the 
loss was largely compensated for by establishing at now breeding tarns or returns to previously used tarns (Table 2).

The mean number of large chicks per year did not differ between tarns with a long and continuous breeding tradition and the other ones (Table 3 ). The tarns with a long breeding tradition were on average occupied during three out of four seasons, whereas the other ones were used less frequently, on average every third year (Table 3 ). Thus, over time, the tarns with a long breeding tradition (sometimes several decades) are especially important for the recruitment.

\section{Dalsland}

Material and methods

The baseline was a survey of the vertebrate fauna in the province of Dalsland done by Karvik (1964) in 1944-1962. The number of occupied tarns and breeding pairs was compared with results from surveys done by Projekt LOM during 1994-2012, i.e. 50 years later.

For the period 1944-1962, and with reference to copies of Karvik's original and hand-written notes, all sites where breeding was confirmed for at least one year, or sites that he judged likely to harbour breeding Red-throated Loons, were counted as breeding sites. For the period 1994-2012, all sites where breeding could be confirmed at least during one year, were counted as breeding sites (following the same methodology as for south-western Sweden); i.e. a more strict assessment than possible for the period 1944-1962.

\section{Results}

Karvik (1964) assessed the breeding population of Red-throated Loon to around 40 pairs, although we find an estimate of 31 breeding sites, holding 32 pairs, to be more accurate after a reassessment of Karvik's original notes. Twenty-one of these 31 sites were visited again during the period 19942012 , with breeding confirmed at five of them (24\%). Thus, for $76 \%$ of the sample of sites identified by Karvik (1964) we could not confirm any breeding 50 years later.

During the period 1994-2012, in total 56 potential breeding tarns were checked at least during one year (often several years), including the 21 sites surveyed also during 1944-1962. Breeding during at least one year was confirmed at 29 sites, holding 31 pairs.

From comparing numbers, it might seem as the number of occupied tarns and breeding pairs have remained constant, but considering the increase of field ornithological activities during the last decades and thus a higher possibilitiy to detect breeding pairs at new sites, a decline of the breeding population cannot be excluded.

Furthermore, there was a substantial redistribution of the breeding sites among the 29 breeding sites localized during 1994-2012, only five (17\%) were identified during 1944-1962. One tarn, judged to be abandoned by Karvik, was reoccupied during 1994-2012.

\section{Hagfors Municipality, Värmland}

Material and methods

Breeding sites included in a survey in Hagfors Municipality, province of Värmland, in 1995 were visited again in 2010 (Borgström 1996, Schütt \& Westerlund 2010). The field work followed the methodology used by Projekt LOM, with a first visit during 25 May-29 June and a second visit during 5 July-3 August. The first visit included 306 tarns, and after exclusion of tarns judged not being attractive for breeding Red-throated Loons, 156 tarns were checked a second time; with complementary visits if needed to follow up initiated breeding or the survival of chicks (Schütt \& Westerlund 2010, for details).

The survey in 1995 was done during 29 June-10 August, so failures during incubation were then overlooked. Thus, comparisons between 1995 and 2010 were primarily based on results from the second visit and with reference to the number of tarns with chicks.

\section{Results}

A redistribution of breeding sites, as well as a decrease of the size of the breeding population during the 15-year period between 1995 and 2010, was confirmed. Number of tarns with Red-throated Loon chicks had declined by $21 \%$ from 33 tarns in 1995 to 26 tarns in 2010. For ten tarns, chicks were recorded both in 1995 and 2010, i.e. that $30 \%$ of the 33 tarns occupied in 1995 were used also in 2010 , and $38 \%$ of the 26 tarns occupied in 2010 were used also in 1995 (Schütt \& Westerlund 2010, for details). 


\section{Discussion}

Redistribution of breeding sites and trends in the population size

From the above surveys it can be concluded that there has been a redistribution of the tarns used by breeding Red-throated Loons. With reference to the results from south-western Sweden, there is an indication that around $30 \%$ of the tarns were abandoned during a period of ten years, whereas almost one quarter of the tarns were "old" breeding sites that had been regularly used during more than 30 years.

The loss of breeding sites was largely compensated for by establishing at new tarns or reoccupation of tarns used in the past. Thus, the decreased number of pairs reported by many volunteers might at least partly be explained by movements to other breeding sites. With reference to previous studies it seems likely that breeding failures, primarily due to predation, is a major reason for abandoning breeding sites, although the tarns may be reoccupied after some years (Dahlén \& Eriksson 2002).

However, we cannot exclude that there also has been a continuous decline in the number of tarns with breeding pairs since the mid of the $20^{\text {th }}$ century. Although the number of sites with confirmed breeding was approximately the same as around 1980 in south-western Sweden, and during the last
50 years in Dalsland, a population decline cannot be ruled out, given an increased ornithological activity during the latest decades and possibly better chances to detect any breeding Red-throated Loons at sites not previously known. For Hagfors Municipality a decline could be clearly confirmed, similar to what was found for the neighbouring Sunne Municipality in surveys done in the mid-1980s and again in 2005 (Schützer \& Schütt 2005).

Applications in management and conservation

A main finding of this study is that the tarns with a long tradition of regular breeding are also used more frequently and may contribute to a substantial part of the recruitment in a long-term perspective. Thus, it is important to localize these tarns and to prioritise their management and protection.

\section{Lessons for future surveys}

The substantial redistribution of the tarns used by breeding Red-throated Loons has monitoring implications. In long-term surveys it is important to also search for pairs at tarns without any previous information about breeding, and at tarns that have been abandoned for some time, to assure a sample size that makes possible meaningful assessments of population trends and breeding success. 